\title{
Development and pretesting of an electronic learning module to train health care professionals on the use of the Pediatric Respiratory Assessment Measure to assess acute asthma severity
}

\author{
Anab R Lehr BSc MD(c) ${ }^{1,2}$, Martha L McKinney MD MPH ${ }^{3}$, Serge Gouin MDCM ${ }^{3}$, \\ Jean-Guy Blais $\mathrm{PhD}^{4}$, MV Pusic ${ }^{5}$, Francine M Ducharme MD MSc ${ }^{1,2,6}$
}

\begin{abstract}
AR Lehr, ML McKinney, S Gouin, J-G Blais, MV Pusic, FM Ducharme. Development and pretesting of an electronic learning module to train health care professionals on the use of the Pediatric Respiratory Assessment Measure to assess acute asthma severity. Can Respir J 2013;20(6):435-441.
\end{abstract}

BACKGROUND: Severity-specific guidelines based on the Pediatric Respiratory Assessment Measure (PRAM), a validated clinical score, reduce pediatric asthma hospitalization rates.

OBJECTIVE: To develop, pretest the educational value of and revise an electronic learning module to train health care professionals on the use of the PRAM.

METHODS: The respiratory efforts of 32 children with acute asthma were videotaped and pulmonary auscultation was recorded. A pilot module, composed of a tutorial and 18 clinical cases, was developed in French and English. Health care professionals completed the module and provided feedback. The performance of participants, case quality and difficulty, and learning curve were assessed using the Rasch test; quantitative and qualitative feedback served to revise the module.

RESULTS: Seventy-two participants (19 physicians, 22 nurses, four respiratory therapists and 27 health care trainees) with a balanced distribution across self-declared expertise (26\% beginner, 35\% competent and 39\% expert) were included. The accuracy of experts was superior to beginners (OR 1.79, 1.15 and 2.79, respectively). Overall performance significantly improved between the first and latter half of cases $(\mathrm{P}<0.001)$. Participants assessed the module to be clear (96\%), relevant (98\%), realistic (94\%) and useful (99\%) to learn the PRAM. The qualitative/quantitative analysis led to the deletion of three cases, modification of remaining cases to further enhance quality and reordering within three levels of difficulty.

DISCUSSION: Using rigorous educational methods, an electronic module was developed to teach health care professionals on use of the PRAM score. Using the back-translation technique, both French and English versions were developed and validated simultaneously. The pilot module comprised a tutorial and three case-scenario sections, and was tested on a target audience of physicians, nurses, respiratory therapists and medical trainees.

CONCLUSION: The final electronic learning module met the clarity and quality requirements of a good teaching tool, with a demonstrated learning effect and high appreciation by health care professionals. Available in French and English, it is offered to facilitate implementation of PRAM-based acute pediatric asthma guidelines.

Key Words: Asthma; Child; Clinical score; Computer-assisted learning; Emergency medicine; Health personnel; Validation studies

E

vidence-based guidelines for the management of acute pediatric Casthma are severity specific (1). In children, the major obstacle to guideline implementation is the assessment of severity. In fact, due to age and/or severity of the exacerbation, nearly all preschoolers and
L'élaboration et la mise à l'essai d'un module d'apprentissage virtuel pour enseigner aux professionnels de la santé à utiliser la mesure d'évaluation respiratoire en pédiatrie pour évaluer la gravité de l'asthme aigu

HISTORIQUE : Des lignes directrices sur la gravité, fondées sur la mesure PRAM d'évaluation respiratoire en pédiatrie, un indice clinique validé, réduisent le taux d'hospitalisation pour l'asthme en pédiatrie.

OBJECTIF : Élaborer un module d'apprentissage virtuel pour enseigner aux professionnels de la santé à utiliser la PRAM, en mettre à l'essai la valeur éducative et la réviser.

MÉTHODOLOGIE : Les efforts respiratoires de 32 enfants atteints d'asthme aigu ont été enregistrés sur vidéo, et leur auscultation pulmonaire, consignée. Un module pilote, composé d'un tutoriel et de 18 cas cliniques, a été élaboré en français et en anglais. Les professionnels de la santé ont terminé le module et donné leurs commentaires. Le rendement des participants, la qualité et la difficulté des cas et la courbe d'apprentissage ont été évalués au moyen du test de Rasch. La rétroaction quantitative et qualitative a permis de réviser le module.

RÉSULTATS : Soixante-douze participants (19 médecins, 22 infirmières, quatre inhalothérapeutes et 27 stagiaires du milieu de la santé), répartis de manière équilibrée selon les compétences qu'ils s'attribuaient (26\% de débutants, $35 \%$ de compétents et $39 \%$ d'experts) ont été inclus dans l'étude. La fiabilité des experts était supérieure à celle des débutants (RR 1,79, 1,15 et 2,79 , respectivement). Le rendement global s'améliorait de manière significative entre la première et la deuxième moitié des cas $(\mathrm{P}<0,001)$. Selon l'évaluation des participants, le module était clair (96\%), pertinent (98\%), réaliste $(94 \%)$ et utile (99\%) pour apprendre la PRAM. L'analyse qualitative et quantitative a suscité la suppression de trois cas, la modification des autres cas pour en améliorer la qualité et le reclassement en trois niveaux de difficulté.

EXPOSÉ : À l'aide de méthodes de formation rigoureuses, un module virtuel a été mis au point pour enseigner aux professionnels de la santé à utiliser l'indice de PRAM. Grâce à la technique de traduction renversée, les versions française et anglaise ont été préparées et validées simultanément. Le module pilote se composait d'un tutoriel et de trois volets de scénarios de cas. Il a été mis à l'essai auprès d'un public cible de médecins, d'infirmières, d'inhalothérapeutes et de stagiaires du milieu de la santé.

CONCLUSION : Le module d'apprentissage virtuel définitif respectait les exigences de clarté et de qualité d'un bon outil d'enseignement, avait un effet d'apprentissage démontré et était grandement apprécié des professionnels de la santé. Offert en anglais et en français, il vise à faciliter la mise en œuvre de lignes directrices sur l'asthme aigu en pédiatrie fondées sur la PRAM.

$48 \%$ of school-age children cannot reproducibly cooperate with spirometry in the emergency department (2). The Pediatric Respiratory Assessment Measure (PRAM), a 12-point clinical score, has emerged as a valid tool for assessing acute asthma severity in children one to 17 years of

${ }^{1}$ University of Montreal; ${ }^{2}$ Research Centre, CHU Sainte-Justine; ${ }^{3}$ Department of Pediatrics; ${ }^{4}$ Département d'administration et fondements de l'éducation, University of Montreal, Montreal, Quebec; ${ }^{5}$ Department of Pediatrics, New York University School of Medicine, New York,

New York, USA; ${ }^{6}$ Department of Social and Preventive Medicine, University of Montreal, Montreal, Quebec

Correspondence: Dr Francine M Ducharme, Department of Pediatrics and of Social Preventive Medicine, Associate Director of Clinical Research,

Research Centre, CHU Sainte-Justine, 3175 Côte Ste-Catherine, Room 7939, Montreal, Quebec H3T 1 C5.

Telephone 514-345-4931 ext 4398, fax 514-345-4822, e-mail francine.m.ducharme@umontreal.ca 
age. It exhibits all the requirements of a good clinical score including internal consistency, inter-rater reliability, discrimination and responsiveness to change $(3,4)$. In two independent pediatric cohort studies, severity-specific guidelines based on the PRAM reduced hospital admission by $20 \%$ (5) and length of stay in the emergency department by approximately $45 \mathrm{~min}(5,6)$. Given its rapid uptake in several academic institutions and multicentre clinical trials $(7-10)$, there is an increasing demand for an efficient means to offer rapid, effective and large-scale training of health care professionals to use the PRAM.

In settings that have implemented the PRAM, learning methods have primarily relied on oral presentations followed by bedside teaching by local champions (Personal communication, R Zemek, Children's Hospital of Eastern Ontario, Ottawa, Ontario; DW Johnson, Alberta Children's Hospital, Calgary, Alberta; and D McGillivray, Montreal Children's Hospital, Montreal, Quebec). Four main difficulties are encountered with this traditional approach, namely: reaching all health care professionals who require training; teaching a score with three sensory (audio, visual and tactile) modalities; ensuring a uniform teaching experience in terms of asthma severity and case difficulty; and assessing acquired competencies. Because the target audience comprises various acute care health professionals (physicians, nurses, respiratory therapists, paramedics and health care trainees) working different shifts, an asynchronous teaching model in which learners could undergo the training anywhere at any time appeared to be advantageous over repeated around-the-clock presentations. Several interactive electronic learning modules to teach cardiac auscultation $(11,12)$ and musculoskeletal physical examination (13) have successfully overcome the challenge of teaching audio, visual and tactile elements, and providing a uniform learning experience (14). Such electronic learning modules have proven to be effective at improving knowledge, problem solving skills and change in practice, thus confirming the acquired competencies (15-17). Consequently, an electronic learning module appears to be the best way to overcome the identified difficulties in teaching the PRAM to a target audience.

The purpose of the present study was to develop, pretest the educational value of and, based on received feedback, revise an electronic learning module to teach health care professionals and trainees on the use of the PRAM score to assess the severity of an acute pediatric asthma exacerbation.

\section{METHODS}

The study was approved by the Institutional Review Board of the Centre Hospitalier Universitaire (CHU) Sainte-Justine (Montreal, Quebec) and Our Lady's Children's Hospital in Ireland. Approval for the former was recognized by the ethics board of the other participating Canadian institutions, in which members and research personnel of Paediatric Emergency Research Canada (PERC) network worked. Informed consent for the audio-visual material acquisition phase was obtained from parents (or legal guardians), and assent from children seven years of age and older. Informed consent was obtained from all participants in the pretest phase.

\section{Audio-visual material acquisition and processing}

The 12-point PRAM has been decribed in detail elsewhere $(4,18)$. Briefly, it consists of five elements: a visual sign (suprasternal retraction); a tactile sign elicited by palpation (contraction of scalene muscles); two audio signs documented on auscultation (air entry and wheezing); and oxygen saturation measured using pulse oximetry. Between February and August 2010, participants in the asthma clinic, emergency department, hospital wards and intensive care unit of the CHU Sainte-Justine were prospectively recruited to cover the entire spectrum of acute asthma severity. Children were eligible if they were 18 months to 17 years of age, presented with asthma, and (and/or their parents) had adequate English or French language skills. Patients with impending respiratory failure or other chronic diseases were excluded.

The participants' suprasternal region was photographed and videotaped using a high-resolution video camera (HDC-TM700, Panasonic,
USA), while respiratory sounds were audiotaped using an electronic stethoscope (Bluetooth electronic 3200, 3M, USA) at eight auscultation areas on each patient. A medical illustrator provided the drawings for the scalene and adjoining muscle positions, and the front and back of a child's thorax. Under the direction of the authors, an audio-visual technician edited and standardized all audio and video recordings. Audio recordings were filtered to remove extraneous noise. The video recordings were edited for clarity. The framing of the photograph and video to exclude, or the addition of a blurry band to cover, the children's eyes enhanced confidentiality. When indicated, some original recordings were deleted and replaced with higher-quality recordings recorded at other auscultation sites or in other patients.

\section{Elaboration of the pilot educational module}

An electronic tutorial explaining the rating of each criterion and the interpretation of the PRAM score was created using PowerPoint (Microsoft Corporation, USA). Eighteen unique clinical cases were elaborated, each comprised of a brief medical history, the visual and audio recordings, and the detailed proposed response. An independent group comprised of two pediatric emergency physicians and a pediatric respiratory therapist provided feedback regarding the structure of the tutorial and clinical cases. Three authors (FM, MM and SG) independently reviewed the proposed correct response of each of the 18 clinical cases and the classification into one of three levels of difficulty; discordance was resolved by consensus. The cases were then grouped in three sections of increasing difficulty, each with specific learning objectives. The French tutorial and cases were translated into English by a professional translator and back-translated to French by another translator; the final French version was compared with the original to ensure concordance. The French and English pilot modules available on DVD were composed of four sections: a tutorial and 18 original clinical cases grouped into three levels of difficulty (each level containing six original cases and two mixed cases, in which the audio records of one case and the video of the other were exchanged).

\section{Pretesting the pilot educational module}

Between August 2010 and November 2011, physicians, nurses, respiratory therapists and medical trainees of the CHU Sainte-Justine, the PERC network in Canada and Our Lady's Children's Hospital in Ireland were invited to participate in pretesting of the module's psychometric properties in the language of their choice. Baseline demographics, self-reported comfort with the chest examination of a child with acute asthma, and previous experience with the PRAM and with e-learning were documented. Each participant individually completed the tutorial and the three case scenario sections. After each case, participants recorded their rating of each of the five PRAM criteria, the total PRAM score, the overall severity classification, their rating of the case difficulty, any technical problems and other comments including suggested corrections to the proposed correct response. After each section, participants completed a brief questionnaire evaluating the time taken for completion, attainment of stated objectives, content clarity, relevance, adequacy, usefulness, case realism, global appreciation and general recommendations. Participants participated in a draw or received $\$ 10$ compensation.

\section{Statistical analysis}

The sample of 60 participants was conservatively selected to achieve $95 \%$ confidence on a two-tailed test that no item calibration was more than 1 logit away from its stable value on the Rasch test; between 27 and 61 participants were required assuming a balanced distribution of participants skills (beginner, competent and expert) (19).

Using standard statistics, the length of completion of the module, the module appreciation on a four-point scale of 0 (strongly disagree) to 3 (strongly agree), and the distribution of correct responses was reported. In combination with other qualitative and quantitative feedback, the polytomous partial credit Rasch model served to explore participants' expertise and assess the case quality and difficulty (20). The Rasch model is a standard measurement model used in education 
to estimate person expertise and item difficulty on the same scale. Briefly, the probability of a correct PRAM score was modelled as a logistic function of the difference between the ability of participants to correctly rate the case and the difficulty of each case. In other words, individuals' ability could be eliminated during the statistical estimation of the case difficulty (item parameter) and vice versa. After ascertaining concordance with the model expectations, the Rasch analysis provided statistics related to case difficulty (item), participants (person) and case-participant (person-item) interaction.

Participants' expertise was confirmed by their PRAM score rating accuracy (as a binary outcome) and analyzed using a generalized estimating equation model, with case order as a time variable (using both a linear and quadratic effect) and expertise as a factor. The performance within each expertise level was analyzed using the Rasch Pearson separation index and presented as the group mean position and SD on the person-item location distribution, negative values indicating that the participants' expertise was lower than the case difficulty.

The quality of each clinical case was scrutinized using the Rasch model fit, the percentage of correct response for each PRAM criterion and for the total PRAM score across each expertise level, and participants' qualitative feedback. These served to identify modifications (editing, deletion and substitution) to the audio and/or video recordings and/or the proposed correct response. The difficulty level of each case was assessed using three constructs, namely: the participant's assessment of the case difficulty; the percentage of correct PRAM score across each expertise level and the item position on the personitem location distribution; and a negative position reflected an easy case (ie, that the mean expertise of all participants was greater than the case difficulty and a positive position represented a difficult case).

The overall learning effect in the PRAM score rating accuracy was examined by the group difference in person location (or Pearson separation index) between the first and latter half of the retained quality cases using a Student's unpaired $t$ test, adjusting for case difficulty. Unfortunately, the two mixed cases per section could not be analyzed according to PRAM criterion due to nonindependence of criteria or by the total PRAM score due to the absence of a comparator because each mixed case pertained to two original cases. Statistical analyses were conducted using SPSS version 20.0 (IBM Corporation, USA) and RUMM 2020 (Rumm Laboratory); P<0.05 was considered to be statistically significant.

\section{RESULTS \\ Acquisition of audio-visual material \\ Thirty-two children 18 months to 15 years of age were enrolled at the CHU Sainte-Justine. Most children were preschoolers (88\%), Caucasian (69\%) and male (56\%), with a preponderance of children with moderate asthma (PRAM score 4 to 7 [44\%]), and with a fair rep- resentation of those with severe airway obstruction (PRAM score 9 to $12[13 \%])$. Adequate representation of age groups, ethnicity, sex and asthma severity in the development of clinical cases was ensured.}

\section{Pretesting of psychometric properties}

Seventy-two individuals were enrolled to pretest the pilot module, including 45 health care professionals and 27 medical trainees with a similar distribution of expertise levels (Table 1). One expert who completed only four cases was removed from the analysis. Forty participants (56\%) completed the French and 32 (44\%) completed the English versions. The median (25th percentile, 75th percentile) completion time of the module was $109 \mathrm{~min}(92,143)$; the tutorial required $24 \min (18,30)$ and each section took $35 \min (27,47), 27 \min (21,35)$ and $24 \mathrm{~min}(17,34)$ to complete for the novice, intermediate and advanced sections, respectively. The overall appreciation of the pilot module was excellent: $89 \%$ to $100 \%$ of participants gave positive feedback to the attainment of stated objectives, content clarity, relevance, adequacy, usefulness, case realism, global appreciation and general recommendations (Table 2)
TABLE 1

\section{Characteristics of participants}

\begin{tabular}{|c|c|}
\hline & n (\%) \\
\hline Health care professionals ${ }^{*}, \mathrm{n}$ & 72 \\
\hline Physicians & $19(26)$ \\
\hline Pediatrician & $7(10)$ \\
\hline Pediatric emergency physician & $9(12)$ \\
\hline Pediatric intensivist & $1(1)$ \\
\hline Other & $2(3)$ \\
\hline Nurses & $22(31)$ \\
\hline Pediatric ward & $4(6)$ \\
\hline Pediatric emergency department & $8(11)$ \\
\hline Other & $10(14)$ \\
\hline Respiratory therapist/physiotherapist & $4(6)$ \\
\hline Trainees & $27(37)$ \\
\hline Fellow & $4(5)$ \\
\hline Interns & $8(11)$ \\
\hline Clerk & $15(21)$ \\
\hline Female sex & $54(75)$ \\
\hline \multicolumn{2}{|l|}{ Years of practice $(n=72)$} \\
\hline 0 to 9 & $47(66)$ \\
\hline 10 to 19 & $12(17)$ \\
\hline 20 to 29 & $5(7)$ \\
\hline$\geq 30$ & $7(10)$ \\
\hline Past e-learning experience & $37(51)$ \\
\hline \multicolumn{2}{|l|}{ Comfort with pediatric chest examination } \\
\hline Novice & $19(26)$ \\
\hline Intermediate & $36(50)$ \\
\hline Advanced & $17(24)$ \\
\hline \multicolumn{2}{|l|}{ Previous experience with PRAM use ${ }^{\dagger}$} \\
\hline Yes & $19(26)$ \\
\hline \multicolumn{2}{|l|}{ Expertise ${ }^{\ddagger}$} \\
\hline Beginner & $19(26)$ \\
\hline Competent & $25(35)$ \\
\hline Expert & $28(39)$ \\
\hline
\end{tabular}

*Participants were recruited through the Pediatric Emergency Research Canada network $(n=26)$, at the CHU Sainte-Justine (Montreal, Quebec) $(n=38)$ and at Our Lady's Children's Hospital (Ireland) ( $n=8)$; 'Participants who reported having previously used the Pediatric Respiratory Assessment Measure (PRAM) in practice; those with previous experience reported having used the PRAM for a median (25th percentile, 75th percentile) of $27(12,36)$ months; $¥$ Based on the self-declared level of comfort with the chest examination of a child with acute asthma and their previous experience with the PRAM, participants' expertise was operationally defined as 'beginner' in those rating themselves as such, 'competent' for those reporting an intermediate comfort level and no experience with the PRAM, and 'expert' for those either with an intermediate comfort level and previous experience with the PRAM or those rating their skills as advanced

Overall, the percentage of correct responses for each of the 18 original cases varied from $22 \%$ to $76 \%$ among experts (Figure 1 ). When a variation of one point around the correct PRAM was accepted to account for interobserver variability, the overall case performance increased from $54 \%$ to $77 \%$ among experts. Experts' overall accuracy was significantly better than that of beginners (OR 1.79, 1.15 and 2.79 , respectively) and showed a trend toward being superior to competent participants (OR 1.18, 0.75 and 1.83 , respectively), adjusting for case order. Taking into account the case difficulty level, the group performance in PRAM rating skill improved significantly on the personitem location between the first half and latter half of cases $(-0.17 \pm 0.33$ versus $0.25 \pm 0.41 ; \mathrm{P}<0.001$ ), attesting to a learning effect.

The percentage of correct responses across expertise levels, participants' assessment of case difficulty and case position on the Rasch test item location provided complementary, yet sometimes conflicting, information on the case difficulty (Table 3 ). With the exception of 


\section{TABLE 2}

Per cent agreement regarding the qualitative assessment of each module according to participants

\begin{tabular}{|c|c|c|c|c|}
\hline \multirow[b]{2}{*}{ Questions } & \multicolumn{4}{|c|}{ Section } \\
\hline & Tutorial & Novice & Intermediate & Advanced \\
\hline The objectives stated in the module were met & $69(100)$ & $69(97)$ & $66(97)$ & $66(97)$ \\
\hline The contents of the module were clear & $69(99)$ & $69(97)$ & $66(92)$ & $66(92)$ \\
\hline The explanations were relevant & $69(100)$ & $66(98)$ & $64(97)$ & $64(97)$ \\
\hline The amount of information presented in the module was adequate & $69(99)$ & $69(100)$ & $66(98)$ & $65(98)$ \\
\hline The level of the information presented in the module was adequate & $69(99)$ & $69(99)$ & $65(97)$ & $65(98)$ \\
\hline The case scenarios were realistic & $58(98)$ & $68(93)$ & $66(89)$ & $65(91)$ \\
\hline The feedback provided was useful and clear & $64(98)$ & $66(100)$ & $65(94)$ & $64(97)$ \\
\hline The module contributed to a better understanding of the PRAM score & $67(100)$ & $69(100)$ & $66(97)$ & $66(97)$ \\
\hline
\end{tabular}

Data presented as $n$ (\%). The novice section pertained to cases originally classified as easy; the intermediate section, to cases originally classified as moderate; and advanced to cases originally classified as difficult

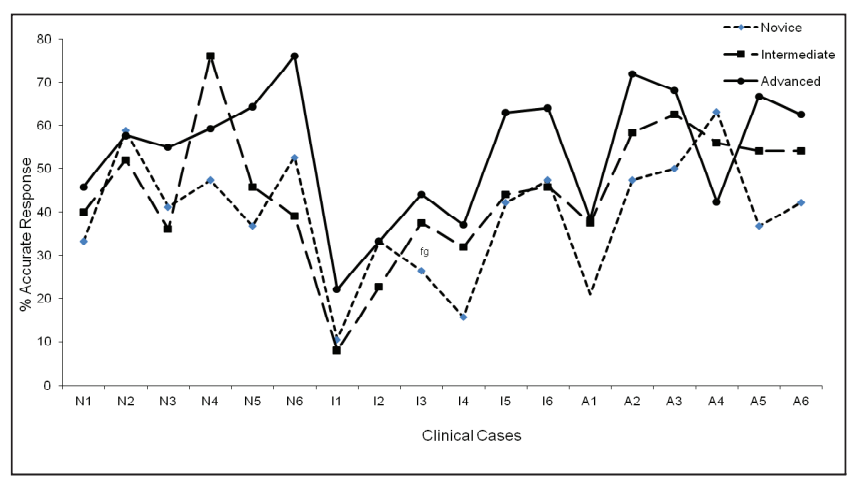

Figure 1) Percentage of correct responses on the y-axis across participants' expertise labelled as novice (dotted line), competent (intermediate) individuals (long dash) and experts (advanced) (solid line). In the pilot module, six cases were originally rated as novice (N1-N6), intermediate (I1-I6) and advanced (A1-A6) and were presented in the order listed on the $\mathrm{x}$-axis

several cases in the advanced section rated as less challenging, participants' assessment of the case difficulty level was generally concordant with the original classification. The item location on the Rasch test suggested some degree of misclassification of difficulty across all sections. In fact, the overall difficulty level of cases was slightly superior to the mean participant expertise, with a negative mean $( \pm S D)$ person position of $-0.34 \pm 0.219$. The qualitative feedback identified the case quality as the source of most of conflicting difficulty ratings and prompted minor or major modifications to each case.

\section{Elaboration of the final module}

Three of the 18 original cases were removed, namely, N3 and I4, which failed to meet the Rasch model assumptions, and A5, whose quality of recording was reported as poor and could not be satisfactorily improved. Whenever competent or expert participants failed a criterion, the confusing section of audio or video recordings in remaining cases were identified; all underwent modifications to maximize quality and to eliminate confusing recordings while making every effort to maintain the original integrity of the case. Of the 15 remaining cases, 10 received minor modifications, that is, changes within an audio or video recording to increase intrarecording homogeneity by deleting confusing breath cycles (eg, wheezing heard in only one of several breaths) or video sections (eg, difficulty to distinguish indrawing from swallowing in a moving child), with no impact on the clinical case's proposed answer; alternatively, a correction in the proposed response was accepted. Five cases underwent major modifications in which poor-quality audio or video recordings were deleted and replaced, affecting the proposed answer. Importantly, to minimize the confusion reported by many participants between inspiratory and expiratory wheezing in a rapidly breathing child, all audio recordings were cut to four respiratory cycles and edited to start on inspiration. Several video recordings were edited for clarity and their length limited to $15 \mathrm{~s}$.
Recognizing the potential impact of these modifications on the final difficulty level, two authors (MM and SG) independently verified the quality and assessed the difficulty of revised cases after all corrections had been made. All decisions were reviewed by a third author (FMD) in light of the objectives specified a priori for the novice, intermediate or advanced sections. These objectives specified that the novice level depicted cases with straightforward criterion rating, the intermediate level dealt with asymmetric findings, difficulties in the assessment of suprasternal retraction and/or pitfalls in PRAM scoring, and the advanced level presented complex cases with subtleties and technicalities in the interpretation of clinical signs. The final module contains five cases in each difficulty level.

\section{DISCUSSION}

Using rigorous educational methods, we developed an electronic module to teach health care professionals about the use of the PRAM score. Using the back-translation technique, both French and English versions were developed and validated simultaneously. The pilot module was comprised of a tutorial and three case scenario sections and was tested on the target audience of physicians, nurses, respiratory therapists and medical trainees. It was rated highly for all criteria including, clarity, realism, relevance and usefulness. As expected, the performance of participants for adequately rating the PRAM varied significantly across expertise levels, with experts performing significantly better than beginners. In light of the performance of expert participants and the apparent misclassification of, and discordance in, the difficulty level of several cases, each case was scrutinized and the quality systematically improved based on qualitative and quantitative feedback. The final e-learning module, composed of a 42-slide tutorial and 15 clinical cases divided in three levels of difficulty, is offered as a training tool to assist in the implementation of PRAM-based acute asthma treatment guidelines in children.

One of the challenges in module conception was simultaneously teaching five PRAM criteria, each dependent on one of three different sensory modalities: audio, visual and tactile. An additional challenge was the acquisition of high-quality and realistic audio-visual recordings. While recordings of respiratory sounds were commercially available, they were usually provided as single examples of given sounds and recorded in different patients; these could not be combined into a realistic case with the eight auscultation areas due to marked variation in respiratory rate, air entry pitch and wheezing pattern. The use of an electronic stethoscope to record breath sounds in acutely ill children with asthma was a salient feature of our module, as were the photograph of the neck and video recordings of suprasternal indrawing in naturally moving sick children. The realism of the cases was agreed on by most participants. The palpation of the contraction of scalene muscles, the only tactile element of the PRAM, was demonstrated in the tutorial by an animated anatomical illustration, instruction around self-palpation during deep inspiration and a demonstration video on a patient. Participants who correctly identified the appropriate palpation area using a click-mouse on the module screen were provided with the findings (presence or absence of scalene contraction) relevant to 
TABLE 3

Psychometric properties and classification of the 18 original clinical cases

\begin{tabular}{|c|c|c|c|c|c|c|c|c|c|c|c|c|c|}
\hline \multirow[b]{3}{*}{ Cases } & \multirow{2}{*}{\multicolumn{3}{|c|}{$\begin{array}{c}\text { Proportion of accurate } \\
\text { response by participants' } \\
\text { self-declared expertise, } \%\end{array}$}} & \multirow{2}{*}{\multicolumn{3}{|c|}{$\begin{array}{l}\text { Participants' assessment of } \\
\text { the case difficulty, } \%\end{array}$}} & \multicolumn{3}{|c|}{ Rasch test* } & \multirow{3}{*}{$\begin{array}{l}\text { Modifications } \\
\text { made }^{\dagger}\end{array}$} & \multirow{2}{*}{\multicolumn{2}{|c|}{$\begin{array}{c}\text { Classification after } \\
\text { modifications }\end{array}$}} & \multirow{3}{*}{$\begin{array}{c}\text { Final } \\
\text { classifica- } \\
\text { tion }\end{array}$} \\
\hline & & & & & & & \multirow{2}{*}{$\begin{array}{c}\text { Item } \\
\text { location }\end{array}$} & \multirow[b]{2}{*}{ Interpretation } & \multirow[b]{2}{*}{$\mathbf{P}$} & & & & \\
\hline & Beginner & Competent & Expert & Easy & Moderate & Difficult & & & & & Expert 1 & Expert 2 & \\
\hline N1 & 33 & 40 & 46 & 87 & 11 & 1 & 1.01 & Difficult & 0.63 & Minor & Easy & Moderate & Difficult ${ }^{\ddagger}$ \\
\hline N2 & 59 & 52 & 58 & 78 & 21 & 1 & 1.18 & Difficult & 0.93 & Minor & Easy & Easy & Easy \\
\hline N3 & 41 & 36 & 55 & 64 & 33 & 3 & -1.26 & Easy & 0.03 & Deleted & Moderate & Easy & - \\
\hline N5 & 37 & 46 & 64 & 69 & 27 & 5 & -0.98 & Moderate & 0.1 & Minor & Easy & Easy & Easy \\
\hline N6 & 53 & 39 & 76 & 74 & 24 & 2 & 2.19 & Difficult & 0.93 & Major & Moderate & Moderate & Moderate \\
\hline \multicolumn{14}{|c|}{ Intermediate } \\
\hline 11 & 11 & 8 & 22 & 13 & 75 & 11 & -1.35 & Easy & 0.52 & Major & Difficult & Difficult & Difficult \\
\hline 12 & 33 & 23 & 33 & 6 & 84 & 10 & -1.1 & Easy & 0.52 & Minor & Moderate & Moderate & Difficult ${ }^{\ddagger}$ \\
\hline 13 & 26 & 38 & 44 & 16 & 73 & 11 & 1.53 & Difficult & 0.46 & Major & Easy & Easy & Moderate§ \\
\hline \multicolumn{14}{|c|}{ Advanced } \\
\hline A1 & 21 & 38 & 38 & 5 & 23 & 72 & -2.1 & Easy & 0.83 & Major & Moderate & Moderate & Moderate \\
\hline A2 & 47 & 58 & 72 & 7 & 38 & 56 & -0.66 & Moderate & 0.25 & Minor & Easy & Easy & Easy \\
\hline A3 & 50 & 63 & 68 & 9 & 50 & 41 & 2.48 & Difficult & 0.46 & Major & Easy & Easy & Moderate§ \\
\hline A4 & 63 & 56 & 42 & 13 & 46 & 41 & -2.59 & Easy & 0.18 & Major & Easy & Easy & Easy \\
\hline A5 & 37 & 54 & 67 & 10 & 20 & 69 & -0.63 & Moderate & 0.67 & Deleted & Difficult & Moderate & - \\
\hline A6 & 42 & 54 & 63 & 17 & 47 & 37 & -0.04 & Moderate & 0.59 & Major & Difficult & Moderate & Difficult \\
\hline
\end{tabular}

*The position of a case on the Person-item location distribution reflects the difficulty of the case in relation to the mean expertise of participants; a negative position indicates an novice case where the mean expertise of participants was greater than the case difficulty, a positive position denotes an advanced case whose difficulty level was superior than the mean participants' skill level, while the position of intermediate cases was closed to 0 . The cases were ranked in order from the easiest (most negative position) to the most difficult (most positive position); ${ }^{\dagger}$ A modification is considered to be: minor when an error in the proposed correction was rectified or changes were made within an audio or video recording to increase intrarecording homogeneity, with no impact on the clinical case's proposed correction; it was considered to be major when audio or video recordings were moved, deleted or replaced, often affecting the clinical case proposed correction. $¥$ Upgraded to 'difficult' because of subtleties and pitfalls in the interpretation of clinical signs in complex clinical situations, meeting the objectives of the advanced module; $\$$ upgraded to 'moderate' because of subtleties in the recognition of indrawing and/or pitfalls in the interpretation of asymmetric findings, meeting the objectives of the intermediate module

the specific case scenario. While the pretest of the pilot module could not confirm the ability to correctly identify the presence or absence of scalene contraction, participants learned the correct palpation area. The pilot module was recognized by participants as meeting the stated objectives. It was highly rated for its clarity, appropriateness of content and feedback, realism of case scenarios and relevance, and was considered to be a useful means of learning to use the PRAM. Importantly, as reported in other electronic modules, we observed a statistically significant improvement in the performance across all participants between the initial and the latter one-half of the cases, confirming that the module provided the expected learning experience.

Two important benefits of the pretesting were the external assessment of case quality and difficulty. As expected, experts performed better than those with self-declared beginners' skills, but not significantly different from that of competent individuals, although the difference approached significance; this was true regardless of whether it was assessed by the person position on the Rasch or the percentage of correct response, suggesting similar competence between nurses experienced in the PRAM and physicians who constituted the expert group and that of nurses and residents untrained in the PRAM who generally constituted the competent group. On average, less than twothirds of experts and competent individuals accurately rated the exact PRAM score as suggested in the proposed answer. The suboptimal performance may be accounted for, in part, by the expected inter-rater reliability previously documented at 0.72 , which would explain a variation of a point above or below the correct response; in fact, the mean performance increased to $77 \%$ when a variation of one point around the correct PRAM was accepted. Participants' performance also varied widely across cases. The Rasch analysis enabled dissociation of the effect of individual skills from that of the case characteristics. We suspect that variation in the case quality interfered with the assessment of case difficulty. The distinction between the latter two was significantly aided by participants' comments.

The quantitative and qualitative feedback led us to make at least minor changes to all cases to reduce nonhomogeneity within the same audio or video recording, remove unclear sounds or video section, and enhance the distinction between inspiration and expiration. While every effort was made to ensure the fidelity of the revised to the original case, some modifications to the PRAM score were inevitable. All cases were reassessed for quality and the accuracy of the PRAM score was independently reviewed and met the approval of two experts. While we did not retest the final module with a new group of participants, we firmly believe the modifications would only have improved the cases' quality and heightened their learning experience; this will be confirmed in a future study to examine, using similar techniques, the performance characteristics of the final module in consenting health care professionals accessing the online module.

We acknowledge the following strengths and limitations. Consistent with other well-accepted asthma tools $(21,22)$, the module was created in an iterative fashion using a rigorous bilingual development process. The feedback from independent experts, followed by pretesting of the module's psychometric properties in a large sample of the target audience of health professions, with an evaluative design using qualitative and quantitative feedback, and appropriate statistics to dissociate individuals' expertise from case quality and difficulty represent significant strengths of this educational project. The case 
selection with a majority of preschoolers reflects reality because most children presenting with an acute asthma exacerbation are $<6$ years of age $(23,24)$. Because the pilot module was available as a PowerPoint presentation with participants' answers recorded on paper, it was possible to verify the correct answer slide before recording their PRAM assessment; thus, we cannot exclude the possibility of an overestimation of performance. Some participants encountered technical difficulty playing certain video or audio recordings on computers with different operating systems and suboptimal video or audio card, resulting in a small proportion (5\%) of missing data. Because the use of mixed cases proved useless, we would recommend selecting one case per difficulty level and offer them as pre- and post-test to ascertain the efficacy of different training methods (ie, online versus conventional teaching). Our study was not designed to test the participants' PRAM accuracy in the real-life setting or to test a potential shorter version. However, the realism of clinical cases, a key feature underlined by participants, has been known to enhance acceptance, effective acquisition skills, retention and satisfaction by the learner; the final module should prove superior to the pilot $(14,25,26)$. The final module will be made available on the University of Montreal (Montreal, Quebec) website (www.childasthmatools.umontreal.ca/PRAM) to facilitate training at the user's most convenient time and place as well as just-intime learning, that is, serving accessible resource when and where the learner needs it $(14,27,28)$.

\section{CONCLUSION}

We developed and validated an electronic learning module, rated by target end-users to be a clear, relevant, realistic and appreciated tool to assess the severity of an asthma exacerbation using the validated PRAM score. It met the essential psychometric properties of a good educational tool - namely, relevance and quality - and demonstrates an important training effect. We are offering this module in French and English versions at www.childasthmatools.umontreal.ca for health care professionals to learn the PRAM and facilitate implementation of PRAM-based pediatric acute asthma guidelines.

ACKNOWLEDGEMENTS: This work was funded through an educational research grant from the Department of Paediatrics of the Centre Hospitalier Universitaire Saine-Justine and the Centre de Pédagogie Appliquée aux Sciences de la Santé (CPASS) of the University of Montreal. Anab Lehr received two consecutive summer bursaries from the Fonds de la Recherche en Santé du Québec (FRSQ) and the Comité d'Organisation du Programme des Stagiaires d'Été (COPSE). The authors acknowledge the support of the FRSQ for the infrastructure support provided to the Research Centre of the CHU Sainte-Justine. They thank the parents and children enrolled in this study for the audio-visual material acquisition. They are indebted to Sylvain Morneau, respiratory therapist of the CHU Sainte-Justine, Dr Chantal Guimont and Dr Dominic Chalut, emergency physicians at the Centre Hospitalier Universitaire de Québec and the Montreal Children's Hospital, respectively, who served as advisory committee and provided feedback on the tutorial and case structure. They thank participating health care professionals in Canada and Ireland who provided feedback on the module. We are indebted to the research assistants, namely, Christopher Abadir, Marie-Ève Blain-Juste, Magdalena Jaworski, Émilie Pineault, Frédérique Plante-Barriault, Yasmine Ratnani, Valérie Tessier, Nicolas Tremblay and Kevin Vézina for recruitment and data entry of patients; Alexandrine Lamontagne for the recruitment and data entry of participants; Manuel Grandmont, Francis Robert and Bertrand Vaillancourt for manipulation of the audio and visual scripts; Madeleine Leduc for the art work; Danielle Buch for assisting in the initial prototype development and, in collaboration with Francine Lacoste, in back-translation of the module; Joanie Gingras for data management; Patrick Charles and Lubomir Alexandrov for data analysis; Anne-Marie Parent and Alexandrine Lamontagne for study coordination; and Annie Théoret for assistance in the manuscript preparation.

AUTHOR CONTRIBUTIONS: Anab Lehr took a leadership role in the conception of the audio-visual module and in modification of the audio-visual recordings; created the case report form to obtain participants' feedback; participated in the recruitment of participants; data entry, analysis and interpretation of results; writing of the manuscript; and revision of the final module under the direct supervision of Dr Francine Ducharme. Martha McKinney and Serge Gouin collaborated in the conception of the module, the editing of the audio-visual frames, and the interpretation of the case scenarios. Jean-Guy Blais supervised the Rasch analysis. Martin Pusic contributed to the protocol and the interpretation of findings. Francine Ducharme conceived the protocol; secured the funding; trained and supervised the research assistants in the data collection of patients and participants; supervised Anab Lehr in every aspect of the development and pretesting for psychometric properties; oversaw the analysis and interpretation; and edited the final module and all versions of the manuscript. All authors approved the final version of the manuscript and module.

\section{REFERENCES}

1. Global Initiative for Asthma (GINA). Global strategy for asthma management and prevention. Global Initiative for Asthma 2012<www.ginasthma.org/> (Accessed August 29, 2013).

2. Gorelick MH, Stevens MW, Schultz T, Scribano PV. Difficulty in obtaining peak expiratory flow measurements in children with acute asthma. Pediatr Emerg Care 2004;20:22-6.

3. Chalut DS, Ducharme FM, Davis GM. The preschool respiratory assessment measure (PRAM): A responsive index of acute asthma severity. J Pediatr 2000;137:762-8.

4. Ducharme FM, Chalut D, Plotnick L, et al. The pediatric respiratory assessment measure: A valid clinical score for assessing acute asthma severity from toddlers to teenagers. J Pediatr 2008;152:476-80.

5. Zemek R, Plint A, Osmond MH, et al. Triage nurse-initiation of corticosteroids in pediatric asthma is associated with improved ED efficiency. Pediatrics 2012;129:671-80.

6. Bhogal S, McGillivray D, Bourbeau J, Benedetti A, Bartlett S, Ducharme FM. Early administration of systemic corticosteroids reduces hospital admission rates in children with moderate and severe asthma exacerbation. Ann Emerg Med 2012;60:84-91.

7. Panickar J, Lakhanpaul M, Lambert PC, et al. Oral prednisolone for preschool children with acute virus-induced wheezing. N Engl J Med 2009;360:329-38.

8. Mauger D, Milton S. Treatment of Preschool Children With Upper Respiratory Tract Illnesses Using Azythromycin and Lower Respiratory Tract Symptoms Using Oral Corticosteroids. (APRIL-OCELOT). Clinical Trial gov 2012;NCT01272635.

9. Schuh S. Inhaled Magnesium in Refractory Pediatric Acute Asthma. Clinical Trial gov 2012;NCT01429415.

10. Gouin S, Robidas I, Gravel J, Guimont C, Chalut D, Amre D. Prospective evaluation of two clinical scores for acute asthma in children 18 months to 7 years of age. Acad Emerg Med 2010;17:598-603.

11. Stern DT, Mangrulkar RS, Gruppen LD, Lang AL, Grum CM, Judge RD. Using a multimedia tool to improve cardiac auscultation knowledge and skills. J Gen Intern Med 2001;16:763-9.

12. Vukanovic-Criley JM, Boker JR, Criley SR, Rajagopalan S, Criley JM. Using virtual patients to improve cardiac examination competency in medical students. Clin Cardiol 2008;31:334-9.

13. Modica RF, Thundiyil JG, Chou C, Diab M, Von SE. Teaching musculoskeletal physical diagnosis using a web-based tutorial and pathophysiology-focused cases. Med Educ 2009;14:13.

14. Gormley G, Bickle I, Thomson C, Collins K. Online learning in clinical skills: The Belfast experience. Clin Teach 2009;6:46-50.

15. Burnette K, Ramundo M, Stevenson M, Beeson MS. Evaluation of a web-based asynchronous pediatric emergency medicine learning tool for residents and medical students. Acad Emerg Med 2009;(Suppl 50):16.

16. Mazzoleni MC, Rognoni C, Finozzi E, Gri T, Pagani M, Imbriani M. E-learning for occupational physicians' CME: A study case. Stud Health Technol Inform 2011;165:111-6.

17. Lam-Antoniades M, Ratnapalan S, Tait G. Electronic continuing education in the health professions: An update on evidence from RCTs. J Contin Educ Health Prof 2009;29:44-51.

18. Chalut D. Toxicological risks of herbal remedies. Paediatr Child Health 1999;4:536-8.

19. Linacre J. Sample Size and Item Calibration Stability. Chicago: Mesa Press, 1994:328. 
20. Wu MA, Adams R. Applying the Rasch model to psycho-social measurement: A practical approach. Educational Measurement Solutions, Melbourne, 2007.

21. Ducharme FM, Davis GM, Noya F, Rich H, Ernst P. The Asthma Quiz for Kidz: A validated tool to appreciate the level of asthma control in children. Can Respir J 2004;11:541-6.

22. Ducharme FM, Noya F, McGillivray D, et al. Two for one: A selfmanagement plan coupled with a prescription sheet for children with asthma. Can Respir J 2008;15:347-54.

23. Canny GJ, Reisman J, Healy R, et al. Acute asthma: Observations regarding the management of a pediatric emergency room. Pediatrics 1989;83:507-12.

24. Lougheed MD, Garvey N, Chapman KR, et al. The Ontario Asthma Regional Variation Study: Emergency department visit rates and the relation to hospitalization rates. Chest 2006;129:909-17.

25. Dror I, Schmidt P, O'connor L. A cognitive perspective on technology enhanced learning in medical training: Great opportunities, pitfalls and challenges. Med Teach 2011;33:291-6.

26. Romanov K, Nevgi A. Do medical students watch video clips in eLearning and do these facilitate learning? Med Teach 2007;29:484-8.

27. Clay CA. Exploring the use of mobile technologies for the acquisition of clinical skills. Nurs Educ Today 2011;31:582-6.

28. Pusic M, MacDonald WA, Cimino J. Just-in-time Learning in the Emergency Department, 2001 <www.ncbi.nlm.nih.gov/pmc/articles/ PMC2243541/pdf/procamiasymp00002-1044.pdf> (Accessed April 1, 2013). 


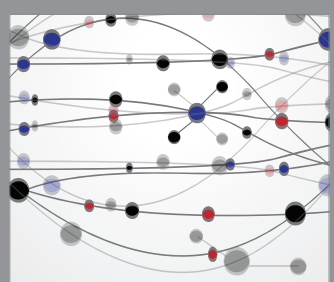

The Scientific World Journal
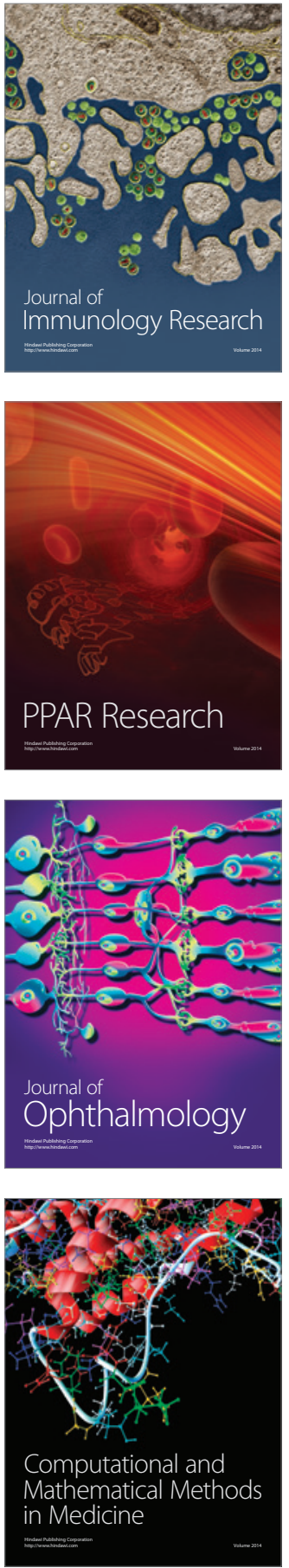

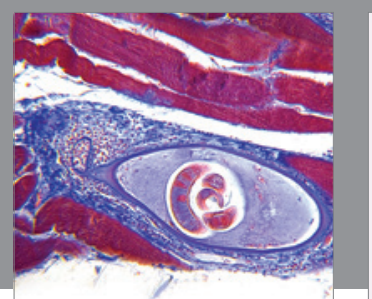

Gastroenterology Research and Practice

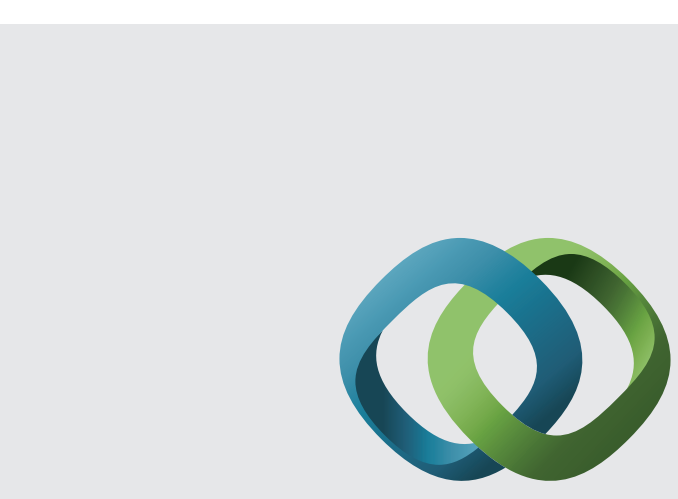

\section{Hindawi}

Submit your manuscripts at

http://www.hindawi.com
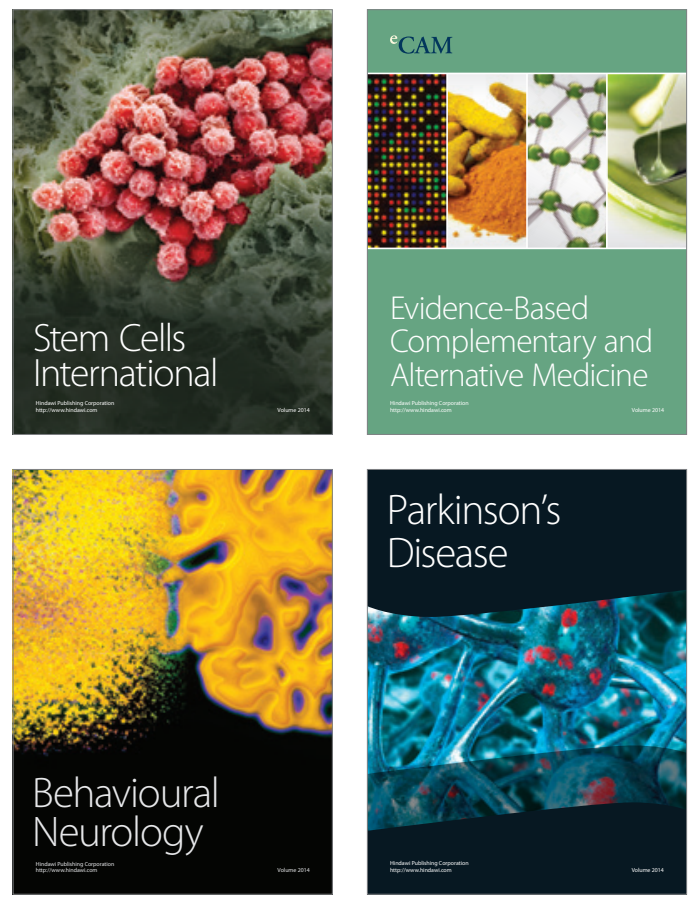
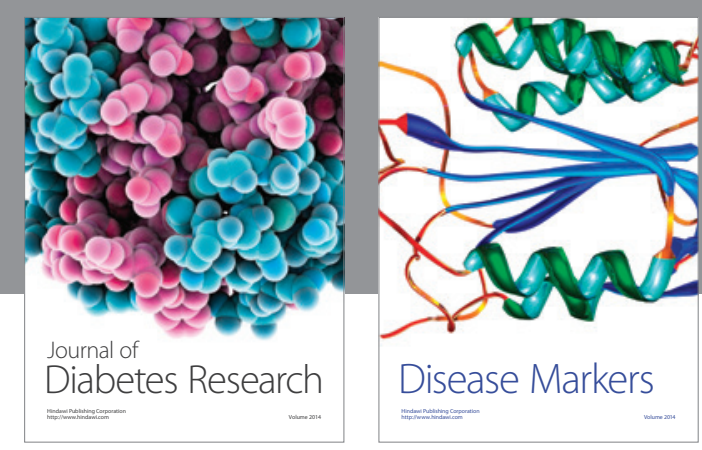

Disease Markers
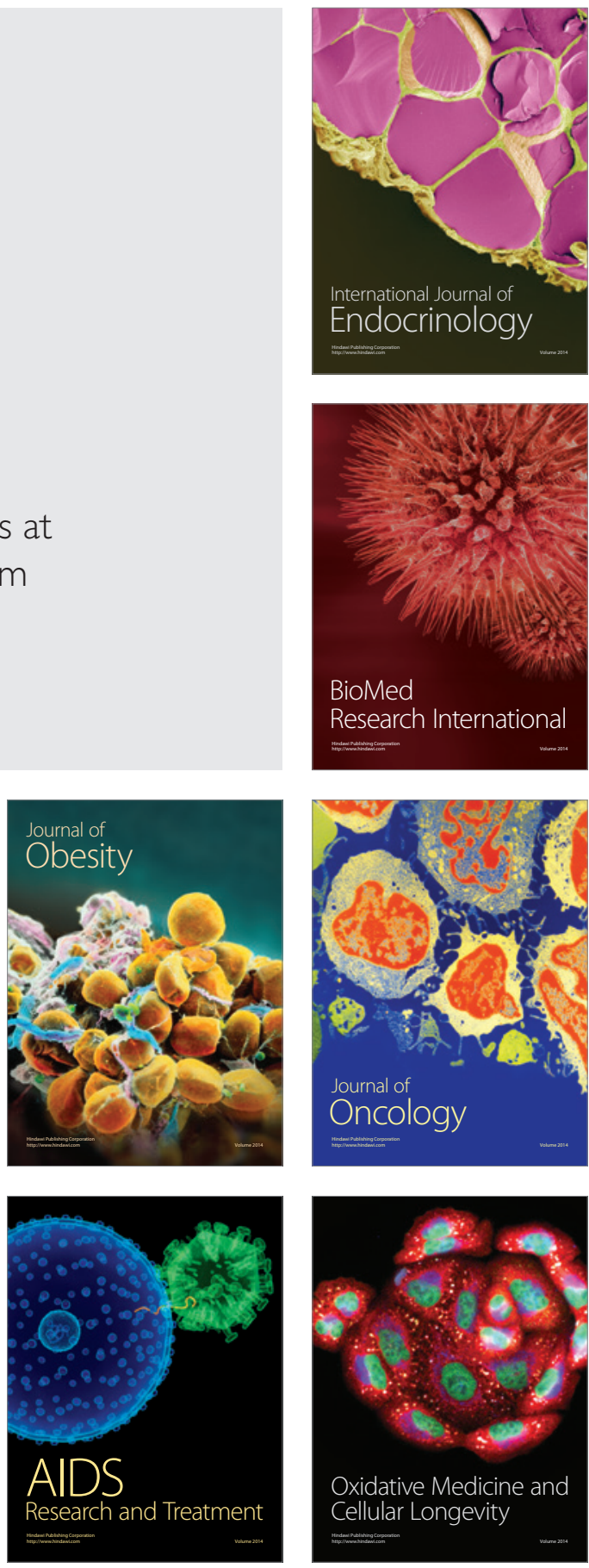